\title{
Pore characterization and its impact on methane adsorption capacity for organic-rich marine shales
}

Yang Wang ${ }^{\text {a, b, c }}$, Yanming Zhu ${ }^{\text {a, b, }{ }^{*} \text {, Shimin Liu }}{ }^{\text {c, }}$, Rui Zhang ${ }^{\text {c }}$

${ }^{a}$ Key Laboratory of Coalbed Methane Resources and Reservoir Formation Process, Ministry of Education, Xuzhou, Jiangsu 221008, China

${ }^{\mathrm{b}}$ School of Resources and Earth Science, China University of Mining and Technology, Xuzhou, Jiangsu 221116, China

${ }^{\mathrm{c}}$ Department of Energy and Mineral Engineering, $\mathrm{G}^{3}$ Center and Energy Institute, The Pennsylvania State University, University Park, PA 16802, USA

*Corresponding Authors: Email: ymzhucumt@126.com; szl3@psu.edu

\begin{abstract}
Shale matrix pore structure controls the gas storage mechanism and gas transport behaviors. We employed various techniques to characterize the complex pore structures of 12 shale samples collected from two marine shale formations in upper Yangtze area in China. The characterization techniques include field emission scanning electron microscopy (FE-SEM), high-pressure mercury intrusion porosimetry (MIP), and low-pressure $\mathrm{N}_{2} / \mathrm{CO}_{2}$ adsorption. The excess methane adsorption capacity was measured for each samples and results were modeled using Langmuir model. Based on the FE-SEM image analyses, micro- and meso-pores within organic matter and inter-particle pores between or within clay minerals are the most commonly developed in these shale samples. Both uni- and multi-modal pore size distributions (PSDs) were observed, and a significant portion of pores are in the pore size range between 3 and $100 \mathrm{~nm}$. It was also found that the micropore $(<2 \mathrm{~nm})$ is the major contributor to the overall specific surface area (SSA), whereas most of the pore volume is occupied by mesopores $(2-50 \mathrm{~nm})$. Two different fractal
\end{abstract}


dimensions, pore surface fractal dimension $\left(\mathrm{D}_{1}\right)$ and spatial geometry fractal dimension $\left(D_{2}\right)$, were estimated from low pressure $N_{2}$ isotherms, with $D_{1}$ ranging between 2.469 and 2.682, and $\mathrm{D}_{2}$ ranging between 2.576 and 2.863 , indicating that the surface and volume of pore structure are heterogeneous. Samples with higher $\mathrm{D}_{1}$ can provide more adsorption sites for methane and tends to have relatively high adsorption capacity, whereas shales with higher $D_{2}$ do not influence the gas adsorption and storage capacities. Methane adsorption capacity increases with the increase of both micropore volume and micropore surface area, and this confirms that microporosity is the governing factor on methane adsorption capacity and storage.

Key words: Shale gas; Pore structure; Fractal dimension; Methane adsorption capacity

\section{Introduction}

Shale gas has become one of the most important energy resources in recent years due to the advancement of well drilling and stimulation technologies. Unlike conventional gas reservoir rocks with micrometer-scale pores, shale is usually dominated by nano- to micrometer-scale pores and has extremely complex pore structure [1]. Pores in shale matrix can be classified into three groups, according to the pore classification system of the International Union of Pure and Applied Chemistry (IUPA): macropores $(>50 \mathrm{~nm})$, mesopores $(2-50 \mathrm{~nm})$ and micropores $(<2$ nm) [2]. Recently, the characterization of the complex pore structure of shale has 
drawn significant attention because the pore structure not only controls the gas storage capacity but influences gas transport dynamics [3-14]. Thus, the quantification of pore structure is critical and essential to estimate the gas storage capacity and to predict gas deliverability at reservoir conditions.

Various pore characterization techniques have been employed to quantify the total porosity, pore volume, specific surface area(SSA) and pore size distribution (PSD) of shale. Shale pore structure can be qualitatively characterized by advanced imaging techniques, including focused ion beam scanning electron microscopy (FIB-SEM) and field emission scanning electron microscopy/transmission electron microscopy (FE-SEM/TEM). These imaging techniques have been successfully used to define shale pore shapes, sizes and distributions $[5,9,12,15]$. The pore volume, SSA and PSD can be quantitatively measured by high-pressure mercury intrusion porosimetry (MIP), low-pressure $\mathrm{N}_{2} / \mathrm{CO}_{2}$ gas adsorption, and ultra-/small angle neutron scattering (USANS/SANS) [4, 6-7, 9, 16-18].

Fractal analysis has been used to quantify the irregularity and surface roughness of porous materials. It has been found that the heterogeneity of pore structures plays an important role in adsorption and diffusion processes [19-23]. Because the gas adsorption capacity is directly related to the irregularity of internal surfaces of shale pores, a surface fractal dimension can be used to depict the relationship between pore surface structure and gas storage capacity. Several pore characterization techniques can be potentially used to estimate fractal dimension, including FE-SEM, small angle 
X-ray scattering (SAXS), MIP and low-pressure $\mathrm{N}_{2}$ adsorption [24-29]. It has been claimed that $\mathrm{N}_{2}$ adsorption/desorption is a time- and cost- effective technique to quantify fractal dimensions [25-26, 30-31]. Compared to the literature on the fractal characteristics of coal [23, 26], few such studies exist for shale [32-34].

The upper Yangtze area (UYA) in China is well known to have great production potential for shale gas. Two prospective marine shale units of Lower Cambrian and Lower Silurian age occur within UYA [35]. Both formations are considered as sweet spots for shale gas exploration because of their thickness, organic richness, widespread occurrence as well as favorable mineral composition [13, 35-36]. However, little is known about methane sorption capacity and storage mechanisms in these two shale formations. Moreover, the detailed pore structure of these shales is not fully characterized. To provide a fundamental understanding of the pore structure and its impact on methane sorption capacity in UYA marine shales, we employed FE-SEM, MIP and low-pressure $\mathrm{N}_{2} / \mathrm{CO}_{2}$ gas adsorption to characterize the pore morphology, pore volume, SSA and PSD of the collected shale samples. In addition, fractal theory was used to quantify the heterogeneity of the pore structure based on low-pressure $\mathrm{N}_{2}$ adsorption data. Combined with the high-pressure methane sorption results, the relationships between the gas sorption capacity and pore volume, SSA, and the fractal dimension were also analyzed and discussed. This study attempted to define the fundamental relationships between the pore structure and gas sorption capacity and laid the foundation for assessment of shale gas resources in UYA. 


\section{Experimental work}

2.1. Sample collection and preparation

Fresh shale outcrop blocks were collected from the sweet gas production spots in UYA located in southwest China. In order to get the fresh samples, short-hole drillings with the depth of 10-60 m were used to obtain high quality outcrop shale samples. A map of sampling locations is shown in Fig. 1. A total of 12 marine shale samples including 7 samples from the Lower Silurian Longmaxi formation and 5 samples from the Lower Cambrian Niutitang formation were collected and prepared. The total organic carbon (TOC) content and methane adsorption capacity of each sample were previously measured in the lab and the results are listed in Table1. The pore structure of each sample was then characterized by FE-SEM characterization, MIP, and low-pressure $\mathrm{N}_{2}$ and $\mathrm{CO}_{2}$ adsorption.

\subsection{FE-SEM characterization}

The FE-SEM imaging of nanopores was performed using the Quanta 200F equipped with an energy-dispersive spectrometer (EDS). In order to get better image quality, the surface of each shale specimen was prepared by Ar ion milling before the FE-SEM imaging. Following this, the pore structure of each specimen was characterized and analyzed based on the SEM images. The SEM imaging was carried out at a constant temperature of $24^{\circ} \mathrm{C}$ and a humidity level of $35 \%$. The qualitative nanopore structure information was interpreted from the obtained images [5] and the detailed results were presented in Section 3.1. 


\subsection{MIP pore characterization and measurements}

The mercury intrusion measurements were conducted using a mercury porosimeter (Auto Pore IV 9510, Micrometrics Instrument) at pressures up to 60,000 psia. This in-house instrument is equipped in the Key Laboratory of Coalbed Methane Resources and Reservoir Formation Process, China University of Mining and Technology. Based on the standard operation guidelines, the pulverized shale samples were prepared and the diameters of shale particles were between 1 and $2 \mathrm{~mm}$. Before MIP measurements, all shale samples were oven dried for over 3 hours at constant temperature of $110^{\circ} \mathrm{C}$.

\subsection{Low-pressure $\mathrm{N}_{2} / \mathrm{CO}_{2}$ adsorption characterization}

Low-pressure (0 101.3kPa) $\mathrm{N}_{2}$ and $\mathrm{CO}_{2}$ isotherm analyses were performed at the Key Laboratory of Coal Preparation \& Purification, China University of Mining and Technology. Prior to the $\mathrm{N}_{2}$ and $\mathrm{CO}_{2}$ adsorption experiments, samples were automatically degassed at $\sim 110^{\circ} \mathrm{C}$ for about 14 hours in a vacuum oven. $\mathrm{N}_{2}$ adsorption data were collected at $77 \mathrm{~K}$ and $\mathrm{CO}_{2}$ adsorption data were collected at $273 \mathrm{~K}$ using Quantachrome Autosorb-1 on 60 mesh samples. The relative pressure $\left(p / p_{0}\right)$ for $\mathrm{N}_{2}$ and $\mathrm{CO}_{2}$ adsorption ranges from 0.009 to 0.995 and 0.0001 to 0.032 , respectively. During the analysis, an automatic equilibrium-detection algorithm was employed to determine when equilibrium had been achieved between the adsorbed and the unadsorbed phases prior to isotherm data collection. The $\mathrm{N}_{2}$ data collected on crushed samples were interpreted using the multi-point Brunauer-Emmett-Teller (BET) 
model for specific surface area and Barrett-Joyner-Halenda (BJH) model for mesopore volume. The Dubunin-Radushkevich (D-R) was used for micropore surface area and the Dubinin-Astakhov (D-A) micropore volume were estimated from the $\mathrm{CO}_{2}$ adsorption analysis [4, 6, 38-39]. A detailed description of these theories can be found in [40].

\subsection{High-pressure methane sorption analysis}

High pressure (up to $\sim 8.5 \mathrm{MPa}$ ) methane sorption isotherms were collected using a volumetric sorption apparatus (IS-300isothermal adsorption/desorption analyzer) manufactured by Terratek, USA. All analyses were performed under isothermal conditions at $30^{\circ}$ C.For each sample, $100-150 \mathrm{~g}$ of pulverized powder sample with particle size less than 60 mesh was used for the high pressure methane sorption measurement.

\section{Results}

3.1. Pore morphology analyses based on FE-SEM images

Qualitative analyses of pore morphology are informative for defining the microscopic pore structures. FE-SEM images show abundant nano-scale pores and a few micron-scale pores. Based on FE-SEM image analyses, the shale matrix pores can be classified into three categories: inter-particle (interP) pores which are located between mineral particles, intra-particle (intraP) pores which are located within mineral particles, and organic-matter $(\mathrm{OM})$ pores that are intra-particle pores located inside the kerogen [41]. All of these pore types, along with microfractures, are 
common in marine shales. OM pores are well-developed in the samples and display such features as pit, oval and honeycomb shapes (Fig. 2a, 2d, and 2f). It is notable that these OM pores can be isolated or inter-connected. In contrast, the inter-particle pores are usually observed around or between grains. These inter-particle pores commonly have polygonal or elongated shaped cross-sections with pore size between tens to about several hundred nanometers (Fig. 2c and 2e). The intra-particle pores are mainly observed in clay minerals and organic matter (Fig. 2b, 2d, and 2e). In addition to these pores, microfractures commonly occur at the interfaces between organic matter and clay minerals (Fig. 2b). The microfracture network provides important avenues for gas transport.

\subsection{Quantitative analyses of pore structure}

To quantitatively characterize the pore structure for micro-, meso- and macro-pores, MIP and low-pressure $\mathrm{N}_{2}$ and $\mathrm{CO}_{2}$ isotherm analyses were employed for all the selected shale samples. Through MIP data analyses, macropore volumes were estimated using the difference between the pore volume at $\phi=50 \mathrm{~nm}$ and $\phi=10^{5} \mathrm{~nm}$ corresponding to the pore diameter between 50 and $10^{5} \mathrm{~nm}$. Mesopore volumes were calculated by the BJH theory based on the $\mathrm{N}_{2}$ adsorption data with pore diameter between 2 and $50 \mathrm{~nm}$. Micropore volumes were estimated by the D-A theory based on the $\mathrm{CO}_{2}$ adsorption data with the pore diameter range between 0.4 and $2 \mathrm{~nm}$.

\subsubsection{Pore structure from MIP measurements}

MIP is routinely used to characterize macropores, especially for micron-sized pores 
$[4,10,16]$. The measured MIP porosities range from 1.13 to $6.69 \%$ for 12 shale samples. The measured results were listed in Table 2. The MIP porosities of these 12 samples were relatively smaller than North American shales with porosities of 3-14\% [42]. As shown in Fig. 3, it was notable that significant portion of total pore volume distributes in the pore size range between 3 to $100 \mathrm{~nm}$ for all shale samples, demonstrating that all the samples are meso- and macro-pore rich. Additionally, both uni- and multi-modal PSDs were observed for these selected samples. The inconsistent of PSDs indicates the strong heterogeneity of pore properties.

The calculated macropore volumes vary from 0.18 to $1.15 \mathrm{~cm}^{3} / 100 \mathrm{~g}$ and the details were listed in Table 2. Here, we also want to point out that significant populations of the micropores and fine mesopores are not necessarily accessible by mercury due to the limitation of MIP $[16,43]$. This is the root reason why the micropores are not detected and quantified in Fig. 3 and thus the gas adsorption methods were essential to characterize and quantify the micropores properties.

\subsubsection{Pore characterization using $\mathrm{N}_{2}$ adsorption isotherms}

Low-pressure $\mathrm{N}_{2}$ gas adsorption analyses were known to be capable to characterize micropores. $\mathrm{N}_{2}$ adsorption/desorption isotherms along with hysteresis patterns can depict the physisorption mechanism and pore structure characteristics of the shales [16]. Following the classification of IUPAC, the hysteresis patterns of all tested shale samples fall into H3-type hysteresis as shown in Fig. 4, indicating that the slit-shaped pores are prevailing pore types [2]. 
The BET surface areas and BJH mesopore volumes were estimated from low-pressure $\mathrm{N}_{2}$ gas adsorption data and were listed in Table 2. The BET internal surface areas of all12 samples range from 3.66 to $19.26 \mathrm{~m}^{2} / \mathrm{g}$. The BJH mesopore volumes range from 0.84 to $2.91 \mathrm{~cm}^{3} / 100 \mathrm{~g}$. It was found that the highest mesopore volume occurs in the sample CX-10. Average pore diameters are estimated between 3.68 and $20.17 \mathrm{~nm}$, which fall into mesopore size range.

The distribution of pore volume with respect to pore size can be displayed as pore size distribution (PSD) curves, including incremental, cumulative, or differential distribution curves $[6,8-9,13,16,44]$. The PSDs of all shale samples obtained from the $\mathrm{N}_{2}$ adsorption analyses are illustrated in Fig.5. The bimodal nature of the PSDs is apparent in the selected samples. One peak is between 1.1 and $1.8 \mathrm{~nm}$, and the other peak is between 3.2 and $4.5 \mathrm{~nm}$.

\subsubsection{Pore characterization using $\mathrm{CO}_{2}$ adsorption isotherms}

Low-pressure $\mathrm{CO}_{2}$ adsorption isotherms for all 12 samples are shown in Fig. 6. Type I adsorption isotherms for all samples verified that selected shale samples are microporous solids. It was found that $\mathrm{CX}-18$ has the lowest $\mathrm{CO}_{2}$-adsorption capacity, suggesting the lowest microporosity. CX-10 was found to have the highest adsorption capacity indicating the highest microporosity among the 12 samples.

Using low-pressure $\mathrm{CO}_{2}$ adsorption data, both D-A micropore volumes and D-R micropore surface areas were estimated and listed in Table2. Among the 12 samples, CX-10 has the highest micropore volume of $1.313 \mathrm{~cm}^{3} / 100 \mathrm{~g}$ and $\mathrm{CX}-18$ has the least 
micropore volume of $0.256 \mathrm{~cm}^{3} / 100 \mathrm{~g}$. The $\mathrm{D}-\mathrm{R}$ micropore surface area ranges from 9.09to $39.24 \mathrm{~m}^{2} / \mathrm{g}$. Average pore diameter is in the range of $0.71-1.64 \mathrm{~nm}$, which is falls into micro-pore domain. The micropore size distributions estimated by density functional theory (DFT) show a major peak between $0.45-0.60 \mathrm{~nm}$ and two minor peaks around $0.35-0.40$ and $0.75-0.90 \mathrm{~nm}$ as shown in Fig. 7.

\subsection{Pore fractal analysis of the shale samples}

Fractal geometry of a pore system can be used to describe the porous structure and surface irregularity of a given solid and it directly influences the sorption and diffusion behaviors [23, 26, 45]. Different methods, such as fractal Langmuir, fractal BET, fractal Frenkel-Halsey-Hill (FHH) and the thermodynamic method, have been proposed to calculate fractal dimension based on gas adsorption isotherm [23, 26, 46-47]. Among these, the FHH model was believed to be effective and reliable for a wide range of rock types [31-32]. Fractal dimensions obtained from FHH model using nitrogen adsorption have been discussed in great detail elsewhere [26, 32].

Here, we presented four FHH plots of $\ln (\mathrm{V})$ vs $\ln \left(\ln \left(\mathrm{P}_{0} / \mathrm{P}\right)\right)$ from $\mathrm{N}_{2}$ adsorption data for samples LQ-1, GS-7, GS-15 and CX-18. The plots were shown in Fig. 8. There were two distinct straight line segments at the whole relative pressure range with different slopes values as illustrated in Fig. 8. These two distinct linear segments were generated at the $\mathrm{P} / \mathrm{P}_{0}$ intervals of $0-0.5$ and $0.5-1$, which show good correlations with all $\mathrm{R}^{2}$ values were greater than 0.95 . This phenomenon may indicate different gas adsorption mechanisms in these two regions. Table 3 presents the regressed values of 
slopes, $\mathrm{K}_{1}$ and $\mathrm{K}_{2}$, and the estimated fractal dimension values, $\mathrm{D}_{1}$ and $\mathrm{D}_{2}$. $\mathrm{D}_{1}$ was found to be smaller than $D_{2}$ for each sample. $D_{1}$ ranges from 2.469 to 2.682, and $D_{2}$ ranges from 2.576 to 2.863 .

\subsection{Methane adsorption capacity for all shale samples}

The excess methane adsorption isotherms were measured and the results were plotted in Fig. 9. At a final pressure of $8.5 \mathrm{MPa}$, the measured methane sorption capacities are ranging from 0.715 to $2.912 \mathrm{~cm}^{3} / \mathrm{g}$ for the Lower Silurian shales and from0.459 to $1.949 \mathrm{~cm}^{3} / \mathrm{g}$ for the Lower Cambrian shales. Generally, the sorption capacities of the Lower Silurian shales were higher than the Lower Cambrian ones. This suggests the Lower Silurian formation might have higher shale gas potential than the Lower Cambrian formation.

Because of its simplicity, the Langmuir adsorption model was chosen to model adsorption behavior. The Langmuir modeled results agree well with the experimentally measured data as shown in Fig. 9. The Langmuir volume $\left(\mathrm{V}_{\mathrm{L}}\right)$ and pressure $\left(\mathrm{P}_{\mathrm{L}}\right)$ were calculated, and the results are presented in Table1. The Langmuir sorption capacities range from 0.43 to $3.50 \mathrm{ml} / \mathrm{g}$ and the Langmuir pressures range from 0.20 to $3.37 \mathrm{MPa}$.

\section{Discussion}

\subsection{Effect of fractal dimensions on methane adsorption capacity}

Methane adsorption capacity varies with the physical properties of shale and with temperature and pressure $[4,48-53]$. However, the effects of the fractal characteristics 
of shale pores on methane adsorption capacity are rarely reported. The two fractal dimensions, $D_{1}$ and $D_{2}$, have different impacts on methane adsorption capacities of the 12 shale samples.

Studies have shown that the discrepancy between isotherms at relative pressure of $0-0.5$ and $0.5-1$ represents different adsorption characteristics, i.e., the isotherms at lower relative pressures represent behavior dominated by Van der Waals forces, whereas the isotherms at higher relative pressures characterize actions dominated by capillary condensations $[2,26,54]$. As previously mentioned, $\mathrm{D}_{1}$ was calculated in the region of $\mathrm{P} / \mathrm{P}_{0}<0.5$. Monolayer adsorption was developed in this region because the $\mathrm{N}_{2}$ gas molecule was orderly adsorbed and arranged on the surface of the pores. Therefore, $D_{1}$ can reflect the surface roughness of the pore structure and represent the surface fractal dimension. However, $\mathrm{D}_{2}$ was calculated using the data at higher pressure $\left(\mathrm{P} / \mathrm{P}_{0}>0.5\right)$, and the monolayer adsorption transits to multilayer adsorption. The gas molecules exhibited capillary condensation. Therefore, $\mathrm{D}_{2}$ can be used to define pore structure irregularity. These conclusions are consistent with other results reported in the literature $[26,34]$.

When the methane sorption capacity was plotted against the two fractal dimensions for the shale samples, it was noted that methane sorption capacity positively correlates with fractal dimension $D_{1}$ as shown in Fig. 10. The higher value of $D_{1}$ indicates rougher internal surfaces at which more active adsorption sites were available for methane. However, no definite trend was observed between methane adsorption 
capacity and the fractal dimension $\mathrm{D}_{2}$ as shown in Fig. 10. This indicates the multi-layer adsorption mechanism was not the prevailing adsorption mechanism. This finding well agrees with our previous study that the BET adsorption model, based on the multi-layer adsorption mechanism, has the worst performance of the tested adsorption models, including Langmuir, BET, D-A and D-R models [37]. Physically, $\mathrm{D}_{2}$ quantities the spatial irregularity of the pore network which do not necessarily correlate with the effective adsorption sites. Similarly, a poor correlation between methane adsorption capacity and $\mathrm{D}_{2}$ has been reported for coals, perhaps for the same reason [26]. However, we want to point out that gas transport properties, such as diffusion, slip flow, and Darcy flow, may be significantly influenced by $D_{2}$ since transport properties were controlled by spatial geometrical dimensions, pore heterogeneity, and interconnectivity. To summarize, higher $\mathrm{D}_{1}$ can be associated with abundant adsorption sites for methane, whereas $\mathrm{D}_{2}$ does not influence gas storage capacity.

\subsection{Effect of pore structure on methane sorption capacity}

Qualitative FE-SEM image analyses, in conjunction with quantitative analyses of pore structure using MIP, $\mathrm{N}_{2}$ and $\mathrm{CO}_{2}$ adsorption analyses, show that the selected shales are dense, with low porosity and well developed nanopores. In order to quantify the full size range of pores in shale, we chose to combine the results obtained from MIP, low pressure $\mathrm{N}_{2}$ adsorptionand low pressure $\mathrm{CO}_{2}$ adsorption. Based on the best performance window for each technique, MIP was used to quantify the 
macroporosity (pore diameter $>50 \mathrm{~nm}$ ); low pressure $\mathrm{N}_{2}$ adsorption was used to quantify the mesoporosity (pore diameter between 2and 50nm); and low pressure $\mathrm{CO}_{2}$ adsorption was used to quantify the microporosity (pore diameter $<2 \mathrm{~nm}$ ). The SSA, pore volume and average pore diameter are presented in Table 2. The contributions from the various pore size to the SSA and pore volume are illustrated in Fig. 11. The results indicate that micropores $(<2 \mathrm{~nm})$ are the major contributors $(56.21-80.95 \%)$ to SSA (Fig. 11a) and the contribution of macropores is negligible (0.05-0.62\%). However, micropores only account for $13.56-37.25 \%$ of total pore volume. Mesopores, by contrast, are the dominant contributors to pore volume, averaging $57.43 \%$ as shown in Fig. $11 b$.

TOC is the most important parameter to define the gas storage capacity. Therefore, it is worthwhile to look closely how TOC correlates with the pore structure and adsorption capacity. The pore volumes were plotted against the TOC content as shown in Fig. 12. It was found that only micro-pore volume positively correlated with TOC, indicating that the micropores mainly occur in organic matter. This result agrees well with the FE-SEM imaging (Fig. 2). The meso- and macro-pore volumes were found to be independent with the TOC content which means these pores mainly occur in the inorganic constituents, such as clay minerals and along mineral grain boundaries as shown in Fig. 2 and 12.

The methane adsorption capacity correlates with micropore volume as shown in Fig.13. Internal surface area exponentially increases with the micropore volume. 
However, the meso- and macro-pores do not significantly contribute to surface area as shown in Fig. 11. Thus, the methane adsorption capacity is largely independent of meso- and macro-pore volumes as shown in Fig. 13.

Methane adsorption capacity increases linearly with specific micropore surface area as shown in Fig. 14. The linear relationships between methane sorption capacity and micropore volume and surface area indicate that microporosity is the governing factor for methane adsorption capacity and storage. Since the micropores occur mainly in organic matter, the shale samples with high organic content are economically important to gas shale production because of their significant microporosity and hence high gas storage potential.

\section{Conclusion}

The pore structure of 12 organic-rich marine shale samples was characterized by FE-SEM, MIP, and low-pressure $\mathrm{N}_{2} / \mathrm{CO}_{2}$ adsorption techniques and the methane adsorption capacity was measured. The major conclusions of this study are as follows:

(1) The FE-SEM images provided the information about the size and morphology of shale pores. For shale, the pore architecture and network is really complex. Microand meso-pores within organic matter and inter-particle pores between or within clay minerals are the most common types in the selected samples.

(2) Size range of shale pore structures were characterized by combining MIP and low-pressure $\mathrm{N}_{2} / \mathrm{CO}_{2}$ adsorption techniques. Results indicate that the micropores $(<2 \mathrm{~nm})$ are the major contributors to SSA, whereas most of the pore volume is 
occupied by mesopores $(2 \sim 50 \mathrm{~nm})$.

(3) Based on MIP characterization, both uni- and multi-modal PSDs were observed, and most pores range in size between 3 and100nm.

(4) For micro- and mesopores, multi-modal PSDs were observed for all the samples based on the results of low-pressure $\mathrm{N}_{2} / \mathrm{CO}_{2}$ adsorption analyses.

(5) Based on the nitrogen adsorption data, two different fractal dimensions, $D_{1}$ and $D_{2}$, were obtained, with $\mathrm{D}_{1}$ range between 2.469 and 2.682 , and $\mathrm{D}_{2}$ range between 2.576 and 2.863 , indicating that the surface and volume of pore structure are heterogeneous. The higher pore surface dimension $\left(D_{1}\right)$ can provide more adsorption sites for methane, whereas shales with higher value of $\mathrm{D}_{2}$ do not influence gas storage capacity.

(6) Methane adsorption capacity increases with micropore volume and micropore surface area and this confirms that micropore is the dominant factor controlling methane adsorption capacity and storage.

\section{Acknowledgment}

The authors would like to thank various organizations for the financial support.

This work was jointly supported by the National Natural Science Foundation of China (No. 41272155), the Major State Basic Research Development Program of China (973Program) (No. 2012CB214702), the US National Science Foundation - Fluid Dynamics Program (CBET-1438398), the China Scholarship Council (CSC), and A 
Project Funded by the Priority Academic Program Development of Jiangsu Higher

Education Institutions.

\section{Reference}

[1] Nelson PH. Pore-throat sizes in sandstones, tight sandstones, and shales: AAPG Bull. 2009; 93: 329-340.

[2] Sing KS, Reporting physisorption data for gas/solid systems with special reference to the determination of surface area and porosity. Pure Appl. Chem. 1985; 57: 603-619.

[3] Ross DJK, Bustin RM. Characterizing the shale gas resource potential of Devonian-Mississippian strata in the Western Canada Sedimentary Basin: application of an integrated formation evaluation. AAPG Bull. 2008; 92 (2): 87-125.

[4] Ross DJK, Bustin RM. The importance of shale composition and pore structure upon gas storage potential of shale gas reservoirs. Mar. Petrol. Geol. 2009; 26(6): 916-927.

[5] Loucks RG, Reed RM, Ruppel SC, et al. Morphology, genesis, and distribution of nanometer-scale pores in siliceous mudstones of the Mississippian Barnett Shale. J. Sediment. Res. 2009; 79(12): 848-861.

[6] Chalmers GRL, Bustin RM, Power IM. Characterization of gas shale pore systems by porosimetry, pycnometry, surface area, and field emission scanning electron microscopy/transmission electron microscopy image analyses: examples from the Barnett, Woodford, Haynesville, Marcellus, and Doig units. AAPG Bull. 2012; 96 (6): 1099-1119.

[7] Chalmers GRL, Ross DJK, Bustin RM, Geological controls on matrix permeability of Devonian gas shales in the Horn River and Liard basins, northeastern British Columbia, Canada. Int. J. Coal Geol. 2012; 103: 120-131.

[8] Clarkson CR, Wood J, Burgis S, et al. Nanopore-structure analysis and permeability predictions for a tight gas siltstone reservoir by use of low-pressure adsorption and mercury-intrusion techniques. SPE Reserv. Eval. Eng. 2012; 15(06): 648-661.

[9] Mastalerz M, He L, Melnichenko YB, et al. Porosity of coal and Shale: insights from gas adsorption and SANS/USANS techniques. Energy Fuel 2012; 26: 5109-5120.

[10] Clarkson CR, Solano N, Bustin RM, et al. Pore structure characterization of North American shale gas reservoirs using USANS/SANS, gas adsorption, and mercury intrusion. Fuel 2013; 103: 606-616.

[11] Mastalerz M, Schimmelmann A, Drobniak A, et al. Porosity of Devonian and 
Mississippian New Albany Shale across a maturation gradient: insights from organic petrology, gas adsorption, and mercury intrusion. AAPG Bull. 2013; 97: 1621-1643.

[12] Milliken KL, Rudnicki M, Awwiller DN, et al. Organic matter-hosted pore system, Marcellus formation (Devonian), Pennsylvania. AAPG Bull. 2013; 97 : 177-200.

[13] Tian H, Pan L, Xiao X, et al. A preliminary study on the pore characterization of Lower Silurian black shales in the Chuandong Thrust Fold Belt, southwestern China using low pressure $\mathrm{N}_{2}$ adsorption and FE-SEM methods. Mar. Petrol. Geol. 2013.48, 8-19.

[14] Furmann A, Mastalerz M, Schimmelmann A, et al. Relationships between porosity, organic matter, and mineral matter in mature organic-rich marine mudstones of the Belle Fourche and Second White Specks formations in Alberta, Canada. Mar. Pet. Geol. 2014; 54: 65-81.

[15] Bernard S, Wirth R, Schreiber A, et al. Formation of nanoporous pyrobitumen residues during maturation of the Barnett Shale (FortWorth Basin). Int. J. Coal Geol. 2012; 103: 3-11.

[16] Kuila U, Prasad M. Specific surface area and pore-size distribution in clays and shales. Geophys. Prospect. 2013; 61: 341-362.

[17] Schmitt M, Fernandes CP, da Cunha Neto JAB, et al. Characterization of pore systems in seal rocks using nitrogen gas adsorption combined with mercury injection capillary pressure techniques. Mar. Petrol. Geol. 2013; 39: 138-149.

[18] Wang Y, Zhu YM, Chen SB, et al. Characteristics of the nanoscale pore structure in Northwestern Hunan shale gas reservoirs using field emission scanning electron microscopy, high-pressure mercury intrusion, and gas adsorption. Energy Fuel 2014; 28(2): 945-955.

[19] Lefebvre Y, Jolicoeur C. Gas-phase adsorption studies of selected probe molecules on powdered silica polymorphs. Colloid Surf. 1992; 63: 67-76.

[20] Pyun SI, Rhee CK, et al. An investigation of fractal characteristics of mesoporous carbon electrodes with various pore structures. Electrochim.Acta. 2004; 49: 4171-4080.

[21] Watt-Smith MJ, Rigby SP, Ralph TR, et al. Characterizations of porous carbon electrode materials used in proton exchange membrane fuel cells via gas adsorption. J. Power Sources 2008; 184: 29-37.

[22] Posnansky O, Guo J, Hirsch S, et al. Fractal network dimension and viscoelastic power law behavior: I. A modeling approach based on a coarse-graining procedure combined with shear oscillatory rheometry. Phys. Med. Biol. 2012; 57: 4023-4040.

[23] Cai YD, Liu DM, Pan ZJ, et al. Pore structure and its impact on $\mathrm{CH}_{4}$ adsorption capacity and flow capability of bituminous and subbituminous coals from Northeast China. Fuel 2013; 103: 258-68.

[24] Radlinski AP, Mastalerz M, Hinde AL, et al. Application of SAXS and SANS in 
evaluation of porosity, pore size distribution and surface area of coal. Int. J. Coal Geol. 2004; 59: 245-271.

[25] Wang YL, Du BY, Dou XM, et al. Study on the pore surface fractal dimension and surface acid-base properties of natural particles around Guanting reservoir. Colloid Surf. A. 2007; 307: 16-27.

[26] Yao YB, Liu DM, Tang DZ, et al. Fractal characterization of adsorption-pores of coals from North China: an investigation on $\mathrm{CH}_{4}$ adsorption capacity of coals. Int. J. Coal Geol. 2008; 73: 27-42.

[27] Liu JX, Jiang XM, Huang, XY, et al. Morphological characterization of superfine pulverized coal particle. Part 4. Nitrogen adsorption and small angle X-ray scattering study. Energy Fuel 2010; 24: 3072-3085.

[28] Qu ZH, Wang GGX, Jiang B, et al. Experimental study on the porous structure and compressibility of tectonized coals. Energy Fuel. 2010; 24: 2964-2973.

[29] Alvarez AC, Passé-Coutrin N, Gaspard S, Determination of the textural characteristics of carbon samples using scanning electronic microscopy images: comparison with mercury porosimetry data. Adsorption 2013; 19: 841-50.

[30] Smith MA, Lobo RF, A fractal description of pore structure in block-copolymer templated mesoporous silicates. Micropor. Mesopor. Mat. 2010; 131: 204-209.

[31] Xu SQ, Zhou ZJ, Yu GS, et al. Effects of pyrolysis on the pore structure of four Chinese coals. Energy Fuel 2010; 24: 1114-1123.

[32] Yang F, Ning Z, Liu H. Fractal characteristics of shales from a shale gas reservoir in the Sichuan Basin, China. Fuel 2014; 115: 378-384.

[33] Liu X, Xiong J, Liang L. Investigation of pore structure and fractal characteristics of organic-rich Yanchang formation shale in central China by nitrogen adsorption/desorption analysis. J. Nat. Gas Sci. Eng. 2015; 22: 62-72.

[34] Wang M, Xue HT, Tian SS, et al. Fractal characteristics of Upper Cretaceous lacustrine shale from the Songliao Basin, NE China. Mar. Petrol. Geol. 2015; 67: 144-153.

[35] Zou CN, Dong DZ, Wang SJ, et al. Geological characteristics and resource potential of shale gas in China. Pet. Explor. Dev. 2010; 37: 641-653.

[36] Huang J, Zou C, Li J, et al. Shale gas generation and potential of the Lower Cambrian Qiongzhusi Formation in the Southern Sichuan Basin, China. Pet. Explor. Dev. 2012; 39: 75-81.

[37] Wang Y., Zhu YM, Liu SM, et al. Methane adsorption measurements and modeling for organic-rich marine shale samples. Fuel 2016; 172: 301-309.

[38] Dubinin MM. Fundamentals of the theory of adsorption in micropores of carbon adsorbents: characteristics of their adsorption properties and microporous structures. Pure Appl. Chem. 1989; 61(11): 1841-1843.

[39] Clarkson CR, Bustin RM. Variation in micropore capacity and size distribution with composition in bituminous coal of the Western Canadian Sedimentary Basin: Implications for coalbed methane potential. Fuel 1996; 75(13):1483-1498.

[40] Gregg SJ, Sing KSW. Adsorption, Surface Area and Porosity, Academic Press, 
London 1982.

[41] Loucks RG, Reed RM, Ruppel SC, et al. Spectrum of pore types and networks in mudrocks and a descriptive classification for matrix-related mudrock pores. AAPG Bull. 2012; 96: 1071-1098.

[42] Curtis JB. Fractured shale-gas systems. AAPG Bull. 2002; 86: 1921-1938.

[43] Bustin RM, Bustin AMM, Cui A, et al. Impact of shale properties on pore structure and storage characteristics//SPE shale gas production conference. Society of Petroleum Engineers 2008.

[44] Clarkson CR, Freeman M, He L, et al. Characterization of tight gas reservoir pore structure using USANS/SANS and gas adsorption analysis. Fuel 2012; 95: 371-385.

[45] Mahamud MM, Novo MF, The use of fractal analysis in the textural characterization of coals. Fuel 2008; 87: 222-231.

[46] Avnir D, Jaroniec M. An isotherm equation for adsorption on fractal surfaces ofheterogeneous porous materials. Langmuir 1989; 5(6): 1431-1433.

[47] Vaimakis TC, Skordilis CS, Pomonis PJ. Alternation of geometrical and fractal dimensions of phosphate ore particles during grinding. J. Colloid Interf. Sci. 1995; 172: 311-316.

[48] Chalmers GRL, Bustin RM. Lower cretaceous gas shales in northeastern British Columbia, part I: geological controls on methane sorption capacity. Bull. Can. Petrol. Geol. 2008; 56: 1-21.

[49] Gasparik M, Ghanizadeh A, Bertier P, et al. High-pressure methane sorption isotherms of black shales from the Netherlands. Energy Fuel 2012; 26(8): 4995-5004.

[50] Zhang TW, Ellis GS, Ruppel SC, et al. Effect of organic-matter type and thermal maturity on methane adsorption in shale-gas systems. Org. Geochem. 2012; 47: $120-131$.

[51] Hao F, Zou H, Lu Y. Mechanisms of shale gas storage: Implications for shale gas exploration in China. AAPG Bull. 2013; 97(8): 1325-1346.

[52] Tan J, Weniger P, Krooss B, et al. Shale gas potential of the major marine shale formations in the Upper Yangtze Platform, South China, Part II: Methane sorption capacity. Fuel 2014; 129: 204-218.

[53] Ma Y, Zhong NN, Li DH, et al. Organic matter/clay mineral intergranular pores in the Lower Cambrian Lujiaping Shale in the north-eastern part of the upper Yangtze area, China: A possible microscopic mechanism for gas preservation. Int. J. Coal. Geol. 2015; 137: 38-54.

[54] Khalili N R, Pan M, Sandı G. Determination of fractal dimensions of solid carbons from gas and liquid phase adsorption isotherms. Carbon, 2000, 38(4): 573-588. 


\section{Tables}

Table 1 Shale sample properties.

\begin{tabular}{cccccc} 
Formation & Sample ID & Location & $\mathrm{TOC}^{*}(\mathrm{wt} \%)$ & $\mathrm{V}_{\mathrm{L}}{ }^{*}(\mathrm{ml} / \mathrm{g})$ & $\mathrm{P}_{\mathrm{L}}{ }^{*}(\mathrm{MPa})$ \\
& LQ-1 & Chongqing & 7.68 & 3.50 & 1.60 \\
& LQ-6 & Chongqing & 4.24 & 2.89 & 1.64 \\
Longmaxi & LQ-9 & Chongqing & 2.18 & 1.77 & 1.89 \\
& LQ-13 & Chongqing & 1.46 & 1.36 & 1.21 \\
& GS-6 & Sichuan & 5.23 & 1.64 & 3.37 \\
& GS-7 & Sichuan & 4.82 & 2.13 & 2.14 \\
& GS-15 & Sichuan & 1.76 & 0.95 & 2.41 \\
& CX-8 & Chongqing & 8.54 & 2.42 & 3.16 \\
& CX-10 & Chongqing & 10.02 & 2.62 & 2.67 \\
\multirow{2}{*}{ Niutitang } & CX-18 & Chongqing & 2.17 & 0.43 & 0.26 \\
\cline { 3 - 5 }$\left(\epsilon_{1}\right)$ & HW-5 & Hunan & 4.40 & 0.79 & 0.20 \\
& HW-9 & Hunan & 3.90 & 0.75 & 0.80 \\
\hline
\end{tabular}


Note: geological age: $\mathrm{S}_{1}$-Lower Silurian; $\mathrm{C}_{1}$-Lower Cambrian ("data from [37]).

Table 2 Structural pore parameters of marine shale samples.

\begin{tabular}{|c|c|c|c|c|c|c|c|c|c|}
\hline \multirow[b]{2}{*}{$\begin{array}{c}\text { Sample } \\
\text { ID }\end{array}$} & \multirow[b]{2}{*}{$\begin{array}{l}\text { Porosity } \\
(\%)\end{array}$} & \multirow[b]{2}{*}{$\begin{array}{c}\mathrm{Hg} \\
\text { macropore } \\
\text { volume } \\
\left(\mathrm{cm}^{3} / 100 \mathrm{~g}\right.\end{array}$} & \multirow[b]{2}{*}{$\begin{array}{c}\mathrm{Hg} \\
\text { macropore } \\
\text { surface } \\
\text { area }\left(\mathrm{m}^{2} / \mathrm{g}\right)\end{array}$} & \multicolumn{3}{|c|}{ Mesopores $\mathrm{N}_{2}$-adsorption } & \multicolumn{3}{|c|}{ Micropores $\mathrm{CO}_{2}$-adsorption } \\
\hline & & & & $\begin{array}{c}\mathrm{N}_{2} \mathrm{BJH} \\
\text { mesopore } \\
\text { volume } \\
\left(\mathrm{cm}^{3} / 100 \mathrm{~g}\right)\end{array}$ & $\begin{array}{c}\mathrm{N}_{2} \\
\text { BET } \\
\text { surface } \\
\text { area } \\
\left(\mathrm{m}^{2} / \mathrm{g}\right)\end{array}$ & $\begin{array}{l}\text { Average } \\
\text { pore } \\
\text { size }\end{array}$ & $\begin{array}{c}\mathrm{CO}_{2} \mathrm{D}-\mathrm{A} \\
\text { micropore } \\
\text { volume } \\
\left(\mathrm{cm}^{3} / 100 \mathrm{~g}\right)\end{array}$ & $\begin{array}{l}\mathrm{CO}_{2} \mathrm{D}-\mathrm{R} \mathrm{A} \\
\text { micropore } \\
\text { surface } \\
\text { area } \\
\left(\mathrm{m}^{2} / \mathrm{g}\right)\end{array}$ & $\begin{array}{l}\text { Average } \\
\text { pore } \\
\text { size }\end{array}$ \\
\hline LQ-1 & 4.02 & 1.15 & 0.17 & 0.84 & 13.81 & 3.68 & 1.18 & 39.24 & 1.44 \\
\hline LQ-6 & 3.04 & 0.46 & 0.09 & 1.60 & 9.57 & 14.48 & 0.93 & 31.29 & 1.28 \\
\hline LQ-9 & 1.72 & 0.26 & 0.04 & 2.29 & 8.11 & 11.97 & 0.75 & 26.00 & 1.28 \\
\hline LQ-13 & 1.13 & 0.18 & 0.02 & 2.24 & 5.83 & 15.71 & 0.83 & 24.87 & 1.33 \\
\hline GS-6 & 2.60 & 0.28 & 0.04 & 1.81 & 8.72 & 9.49 & 0.99 & 29.77 & 1.64 \\
\hline GS-7 & 6.69 & 0.79 & 0.27 & 1.71 & 8.41 & 9.29 & 1.04 & 34.89 & 1.31 \\
\hline GS-15 & 4.96 & 0.52 & 0.12 & 1.59 & 9.03 & 8.04 & 0.73 & 26.65 & 1.49 \\
\hline $\mathrm{CX}-8$ & 3.28 & 0.36 & 0.02 & 2.31 & 12.18 & 8.32 & 0.96 & 27.00 & 0.71 \\
\hline
\end{tabular}




\begin{tabular}{cccccccccc} 
CX-10 & 5.25 & 0.42 & 0.12 & 2.91 & 19.26 & 5.82 & 1.31 & 32.30 & 1.52 \\
CX-18 & 1.50 & 0.39 & 0.02 & 1.24 & 3.66 & 14.35 & 0.26 & 9.09 & 1.52 \\
HW-5 & 1.13 & 0.38 & 0.01 & 2.10 & 11.16 & 8.48 & 0.51 & 14.34 & 1.44 \\
HW-9 & 2.16 & 0.53 & 0.04 & 1.04 & 4.45 & 20.17 & 0.58 & 16.44 & 1.35 \\
\hline
\end{tabular}

Table 3 Fractal dimensions of marine shale samples.

\begin{tabular}{|c|c|c|c|c|c|c|}
\hline \multirow{2}{*}{ Sample ID } & \multicolumn{3}{|c|}{$\mathrm{P} / \mathrm{P}_{0}: 0-0.5$} & \multicolumn{3}{|c|}{$\mathrm{P} / \mathrm{P}_{0}: 0.5-1$} \\
\hline & $\mathrm{K}_{1}$ & $\mathrm{D}_{1}=3+\mathrm{K}_{1}$ & $\mathrm{R}_{1}{ }^{2}$ & $\mathrm{~K}_{2}$ & $\mathrm{D}_{2}=3+\mathrm{K}_{2}$ & $\mathrm{R}_{2}{ }^{2}$ \\
\hline LQ-1 & -0.318 & 2.682 & 0.988 & -0.137 & 2.863 & 0.969 \\
\hline LQ-6 & -0.425 & 2.575 & 0.999 & -0.349 & 2.651 & 0.999 \\
\hline LQ-9 & -0.419 & 2.581 & 0.998 & -0.324 & 2.676 & 0.994 \\
\hline LQ-13 & -0.476 & 2.524 & 0.998 & -0.372 & 2.628 & 0.998 \\
\hline GS-6 & -0.391 & 2.609 & 0.998 & -0.271 & 2.729 & 0.994 \\
\hline GS-7 & -0.412 & 2.588 & 0.999 & -0.265 & 2.735 & 0.991 \\
\hline GS-15 & -0.433 & 2.567 & 0.998 & -0.244 & 2.756 & 0.981 \\
\hline CX-8 & -0.399 & 2.601 & 0.998 & -0.255 & 2.745 & 0.986 \\
\hline CX-10 & -0.367 & 2.633 & 0.997 & -0.161 & 2.839 & 0.954 \\
\hline CX-18 & -0.531 & 2.469 & 0.996 & -0.353 & 2.647 & 0.995 \\
\hline & & & 24 & & & \\
\hline
\end{tabular}




\begin{tabular}{lllllll} 
HW-5 & -0.380 & 2.620 & 0.998 & -0.253 & 2.747 & 0.998 \\
HW-9 & -0.476 & 2.524 & 0.998 & -0.424 & 2.576 & 0.999 \\
\hline
\end{tabular}

\section{Figures}

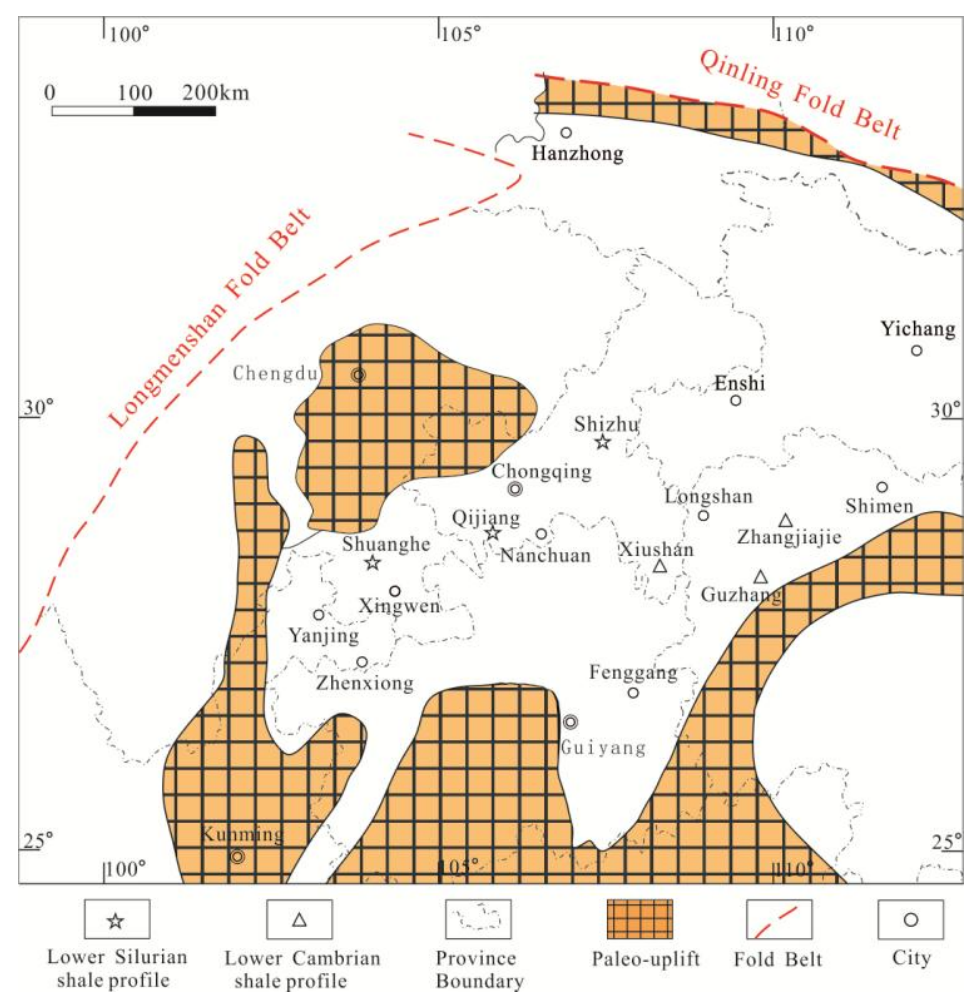

Fig. 1. Geographical map of upper Yangtze area (UYA) and sampling locations (Wang et al., 2016).
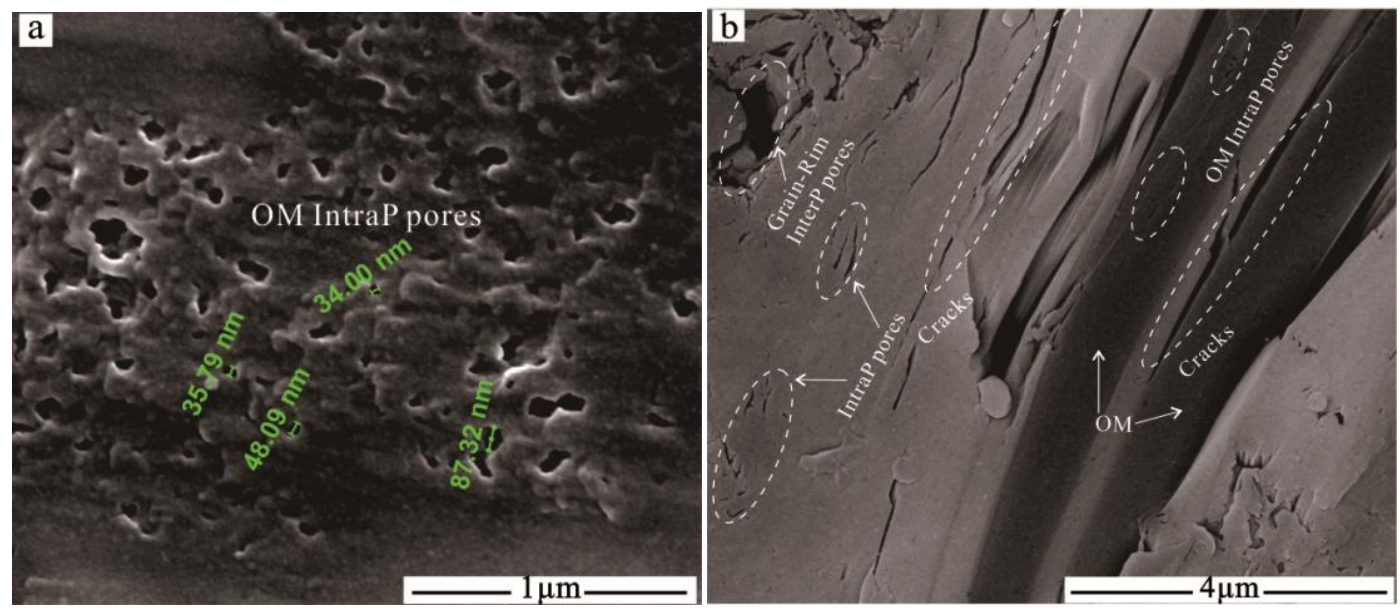

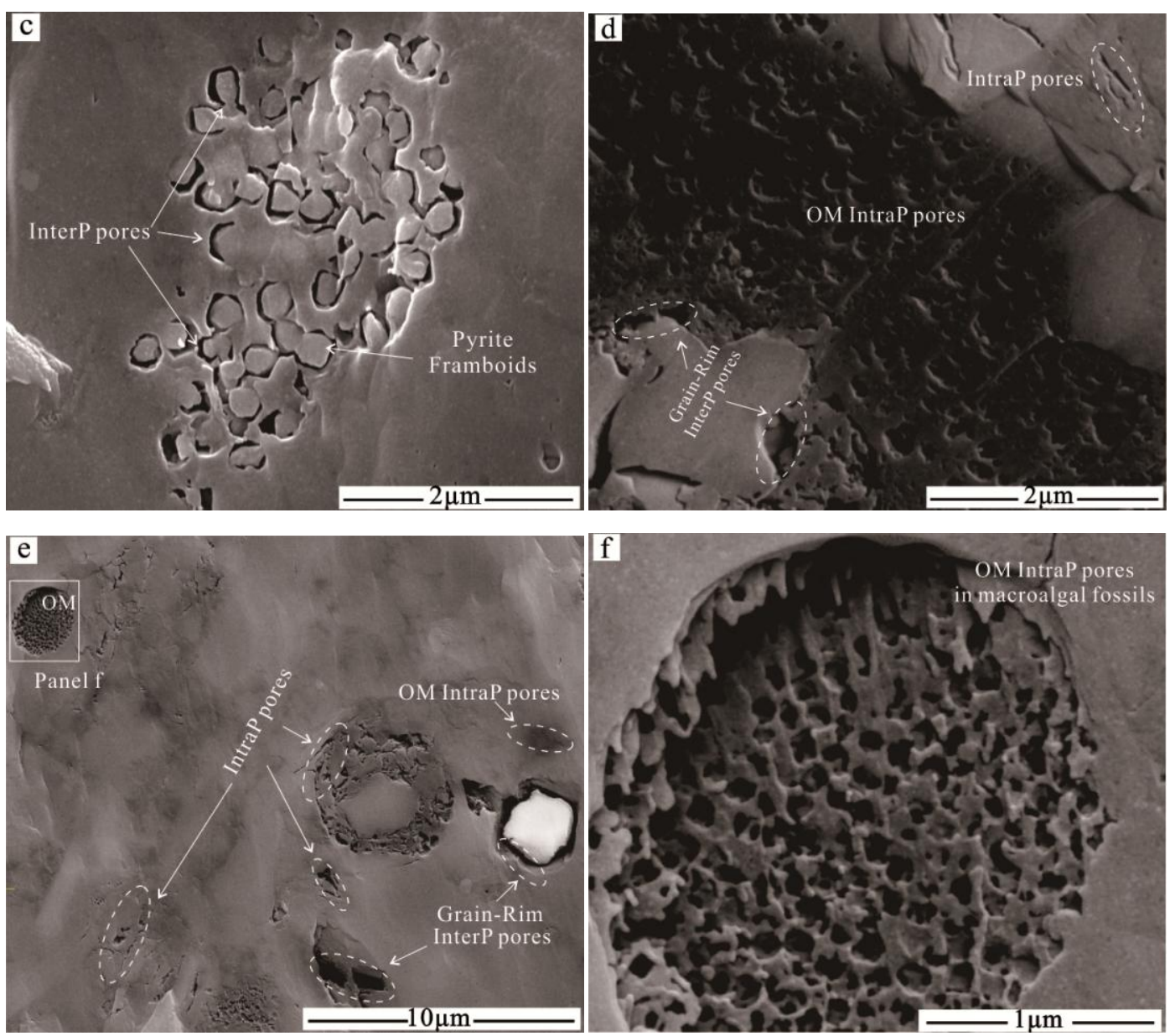

Fig. 2. FE-SEM images of marine shale: (a) the intraP pores in OM; (b) cracks between the organic matter and clay minerals; (c) the interP pores in pyrite framboids; (d) small intraP pores in $\mathrm{OM}$ and interP pores between mineral grains; (e) grain-rim interP pores and the intraP pores developed in limited area of OM; (f) enlargement of the frame in panel e.
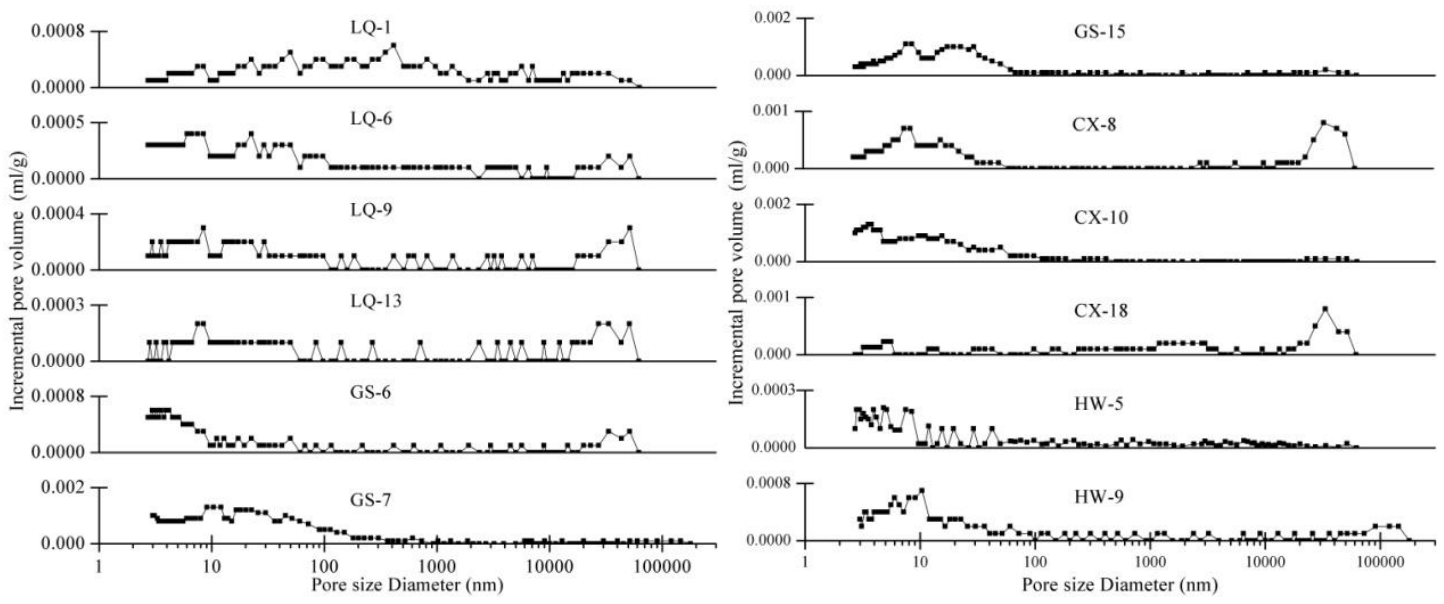

Fig. 3. PSDs of shales estimated by incremental pore volume from MIP analyses. 


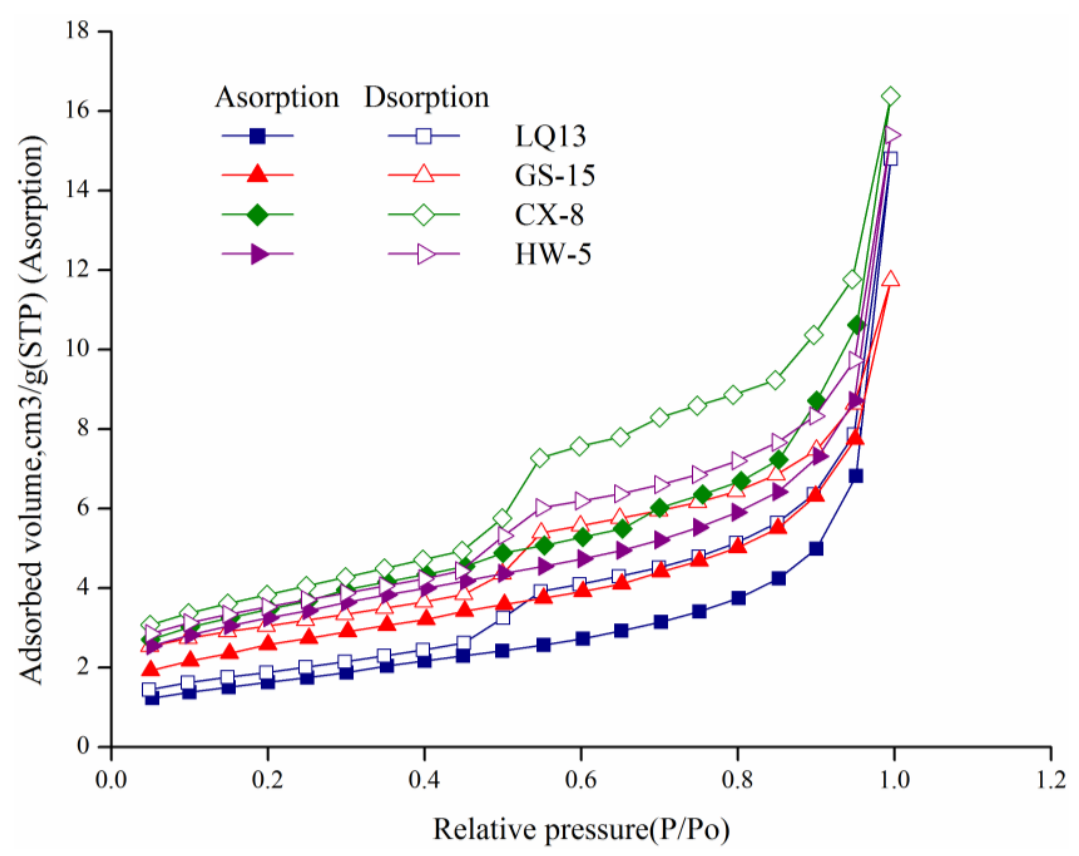

Fig. 4. $\mathrm{N}_{2}$ adorption-desorption isotherms of 4 selected shale samples.

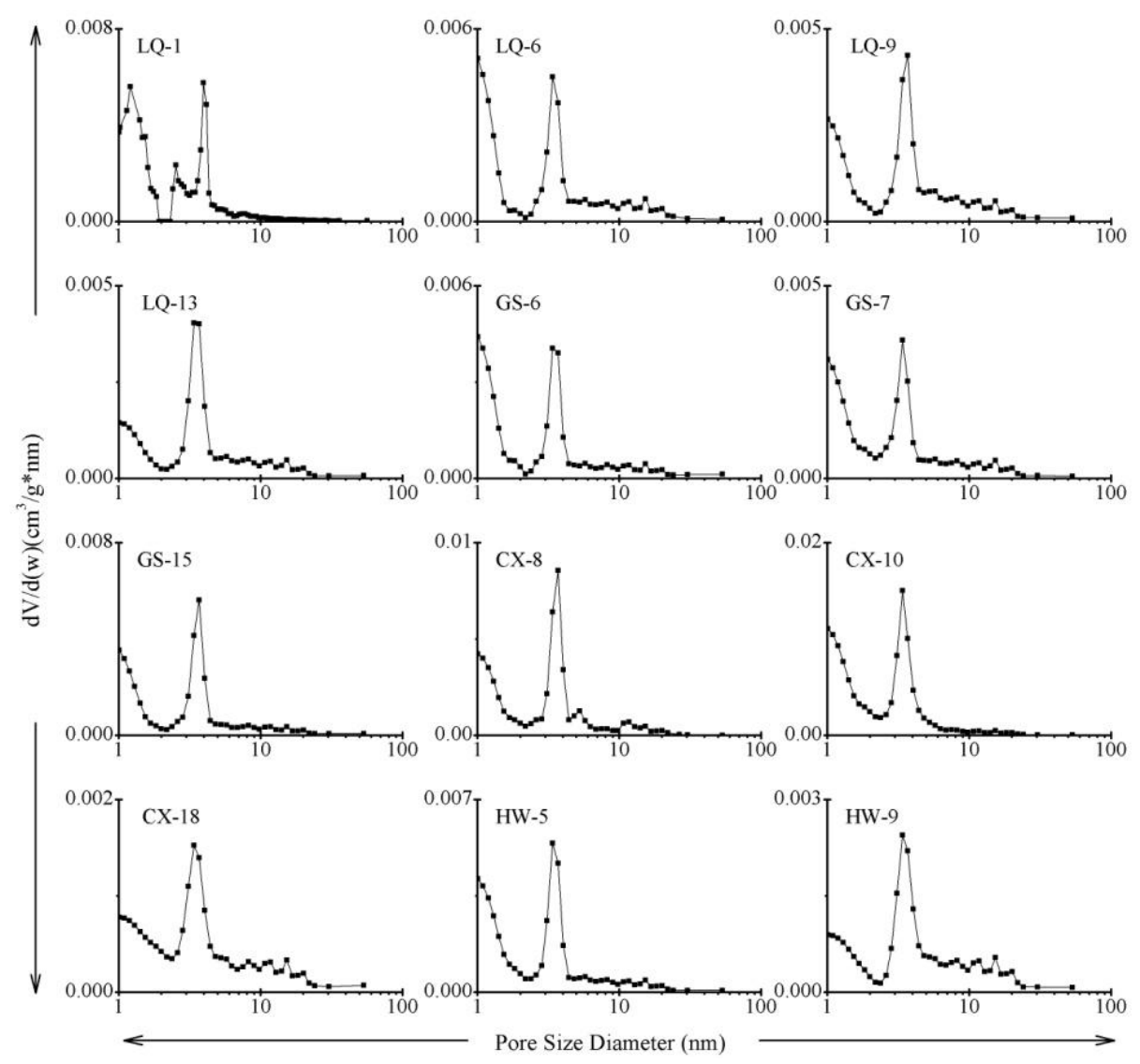

Fig. 5. PSDs obtained fromlow-pressure $\mathrm{N}_{2}$ adsorption isotherms. 


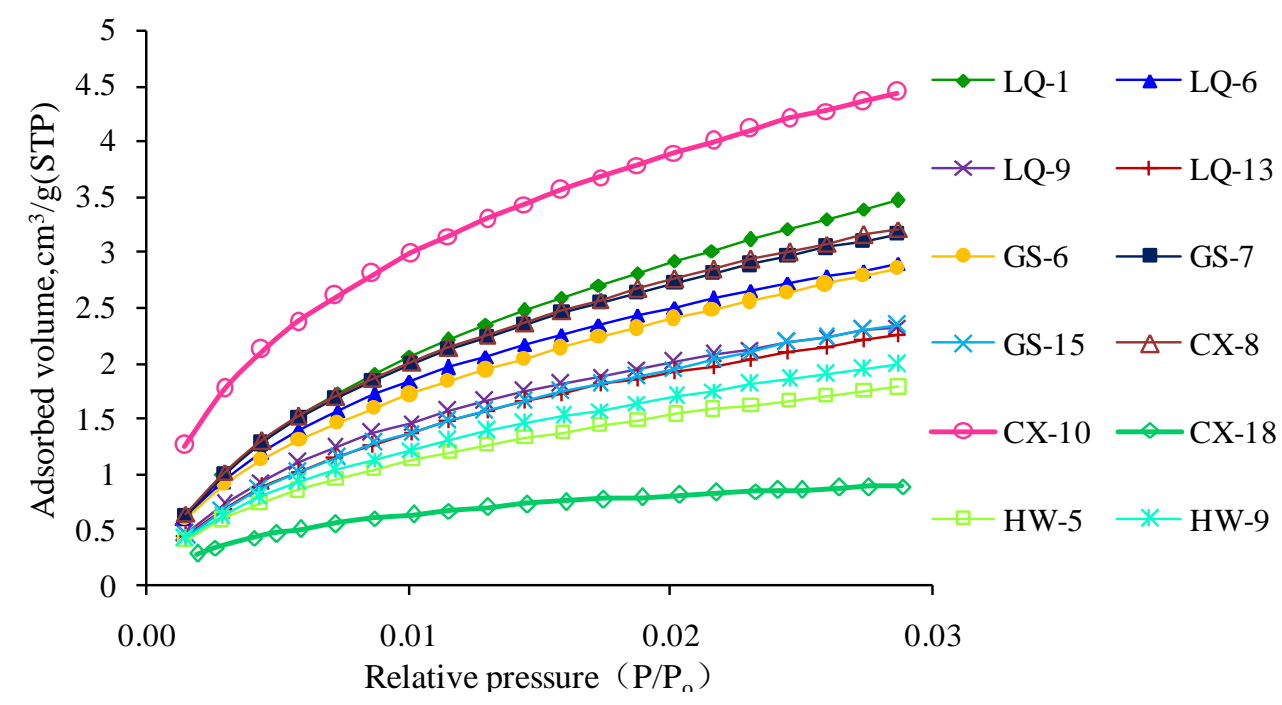

Fig. 6. Low-pressure $\mathrm{CO}_{2}$ adsorption isotherms at $273 \mathrm{~K}$ for the marine shale samples.

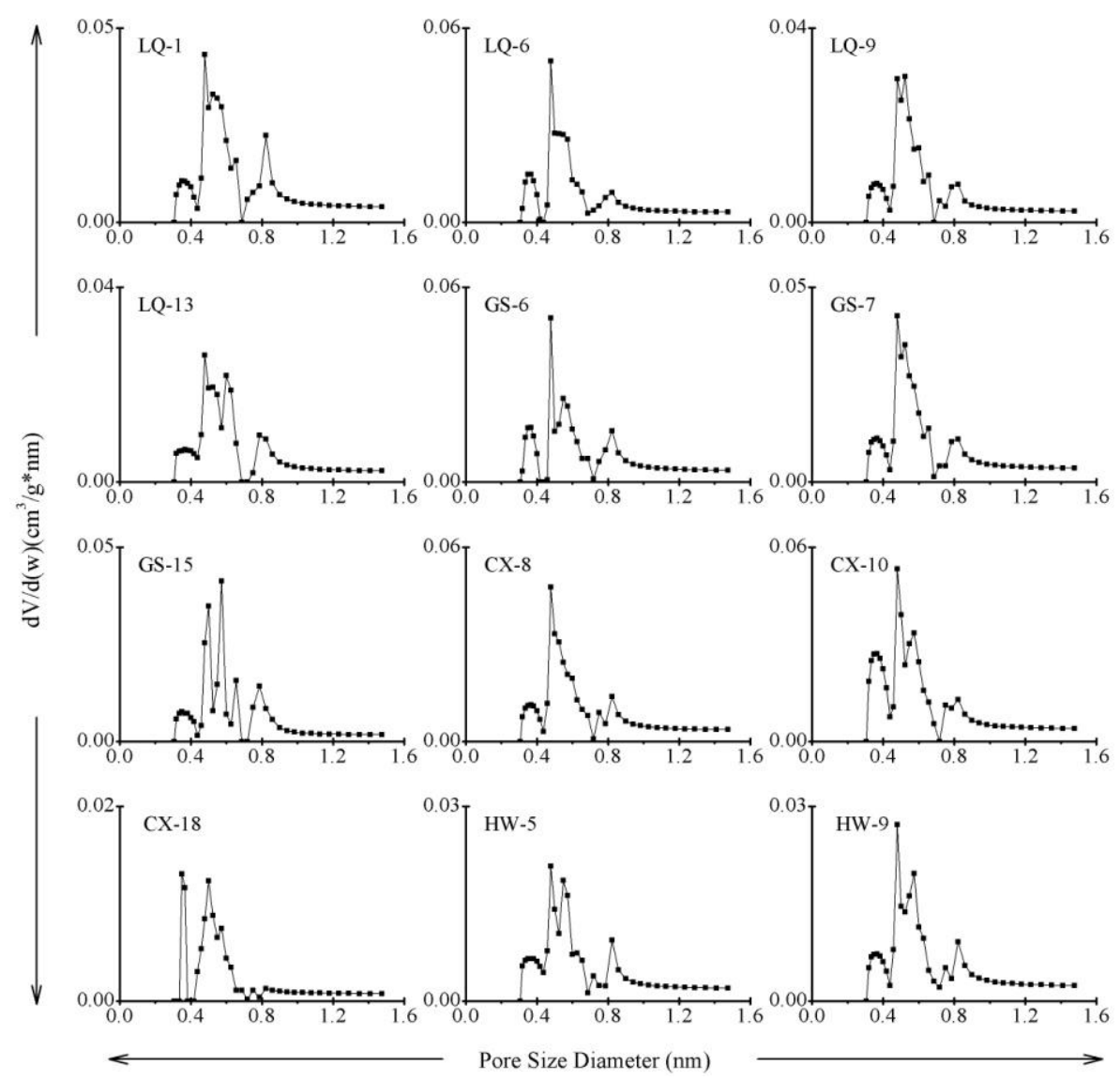

Fig. 7. PSDs obtained from low-pressure $\mathrm{CO}_{2}$ adsorption isotherms. 

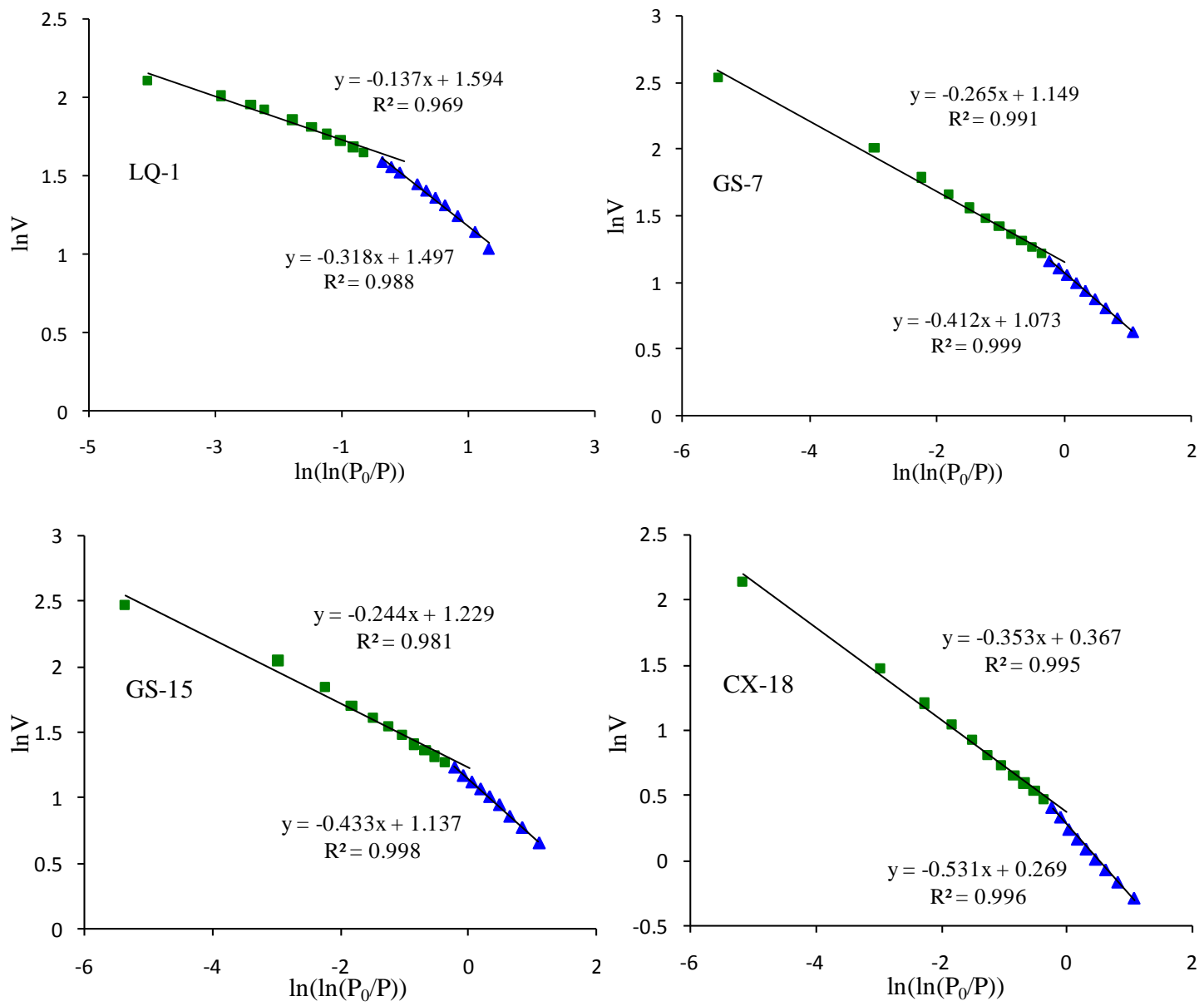

Fig. 8. Plots of $\ln (\mathrm{V})$ vs $\ln \left(\ln \left(\mathrm{P}_{0} / \mathrm{P}\right)\right)$ reconstructed from low-pressure $\mathrm{N}_{2}$ adsorption isotherms for four representative shale samples.
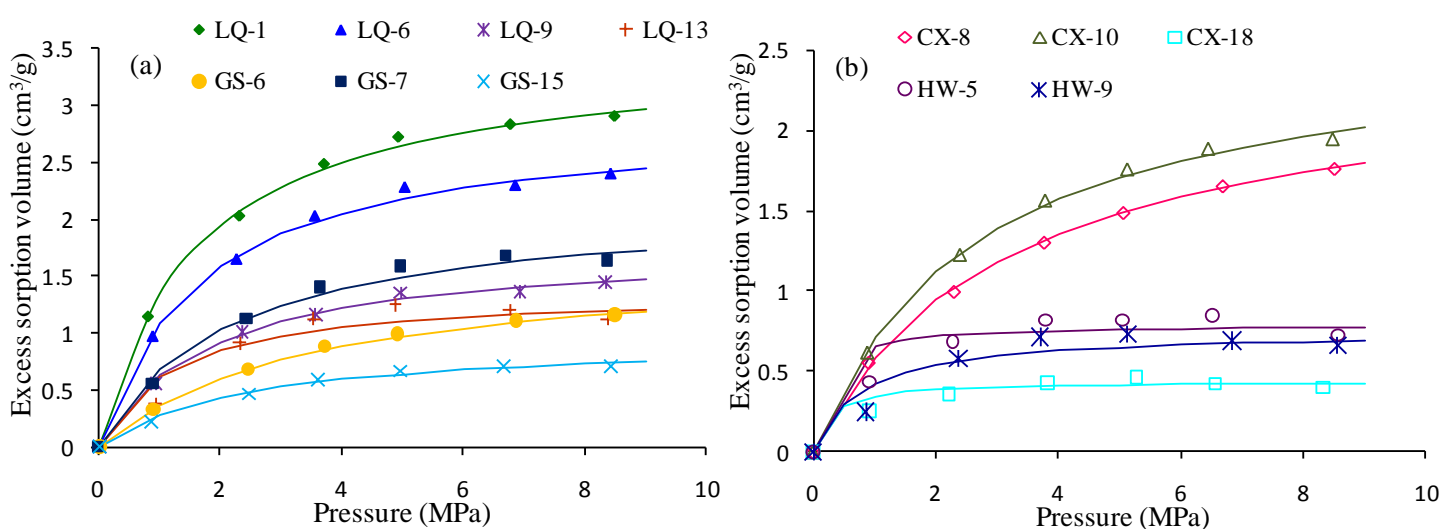
Fig. 9. Methane excess adsorption isotherms for all 12 samples: (a) Lower Silurian Longmaxi shale; (b) Lower Cambrian Niutitang shale.

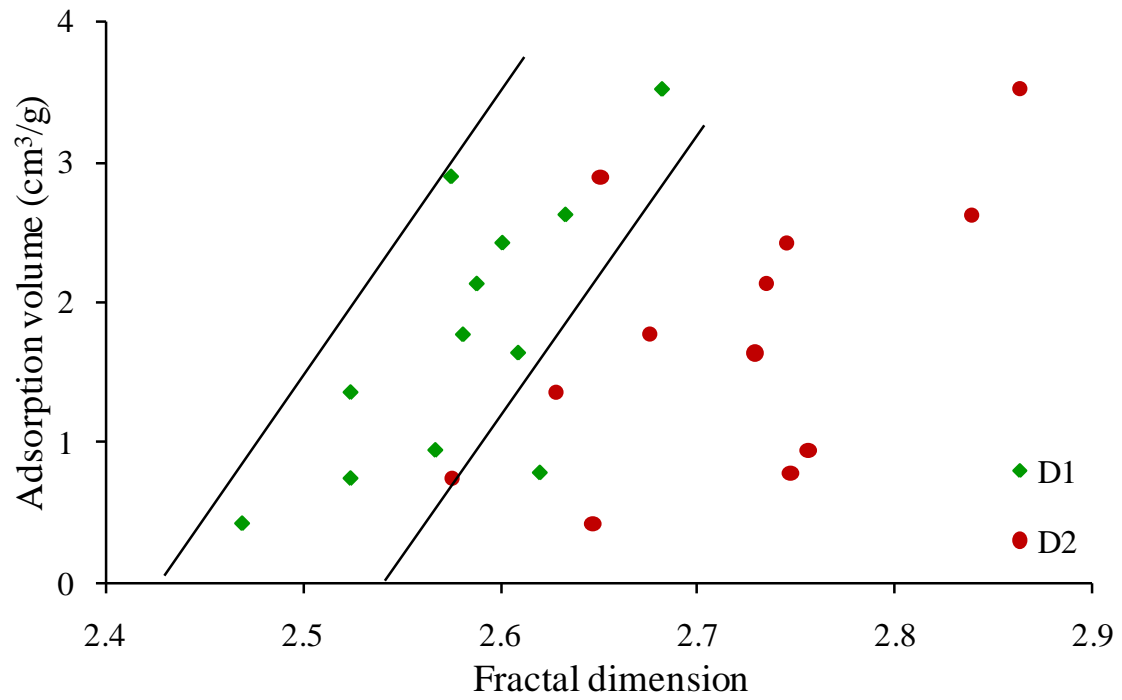

Fig. 10. Relationship between the fractal dimension and the methane adsorption capacity.
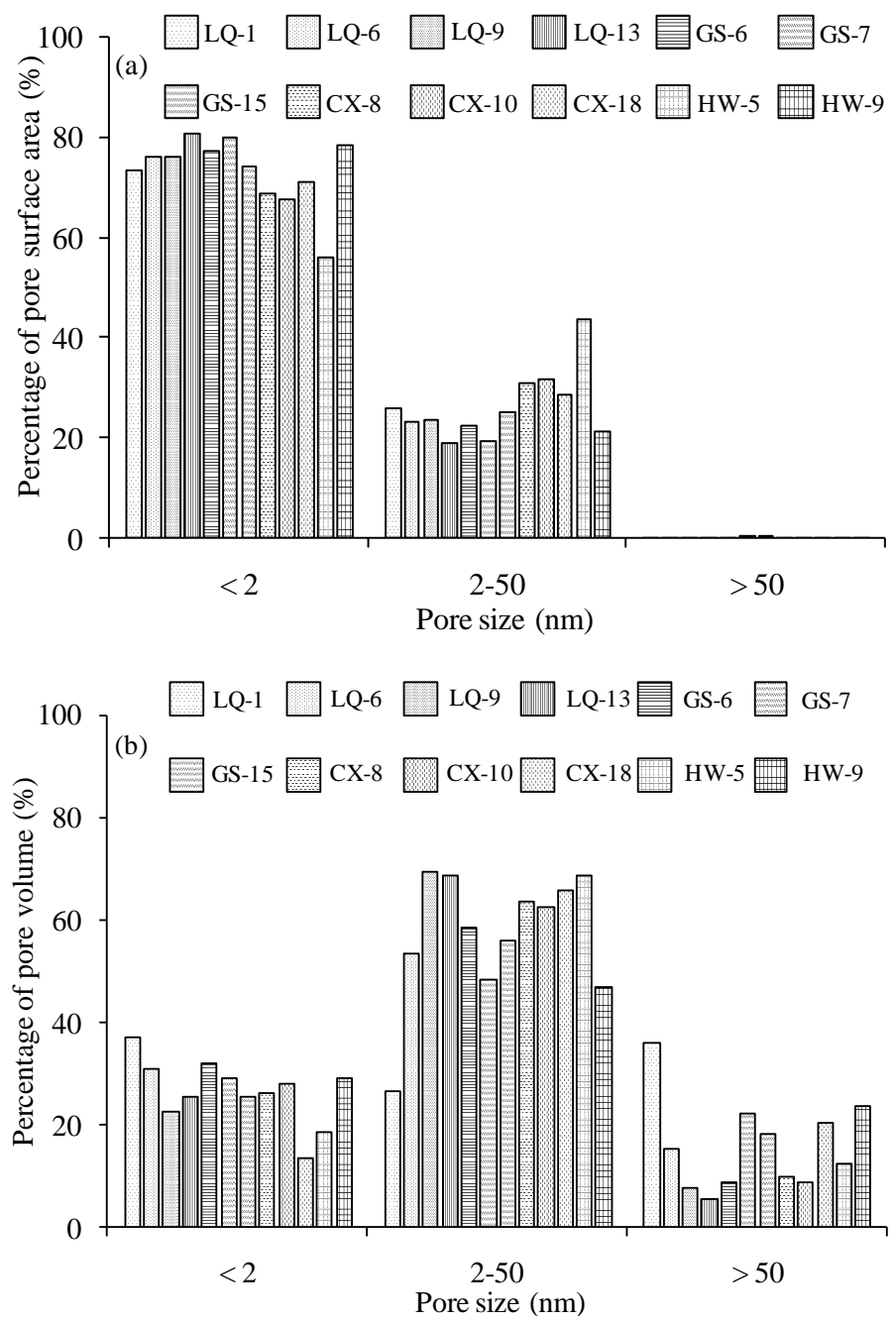

Fig. 11. Pore surface area (a) and pore volume (b) distributions based on IUPA pore 
classification.

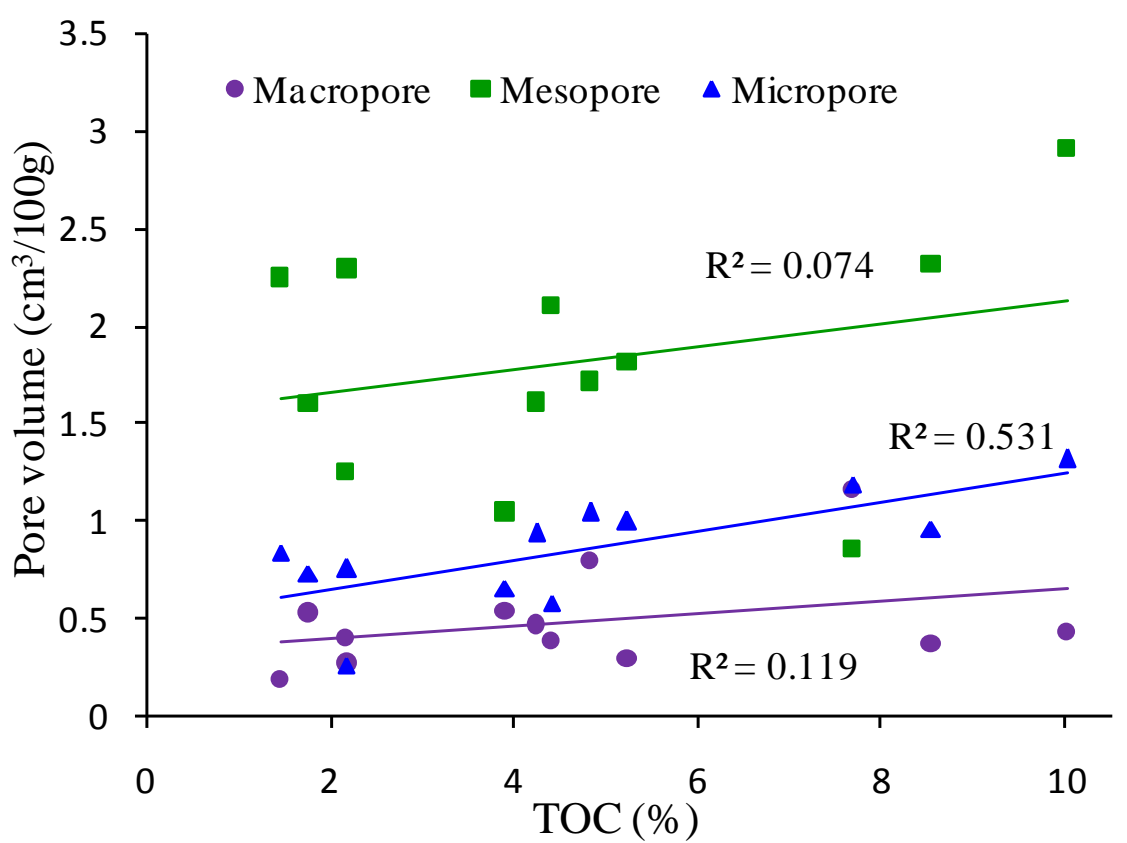

Fig. 12. Relationship between the pore volume and the TOC content for micro-, meso- and macro-pores.

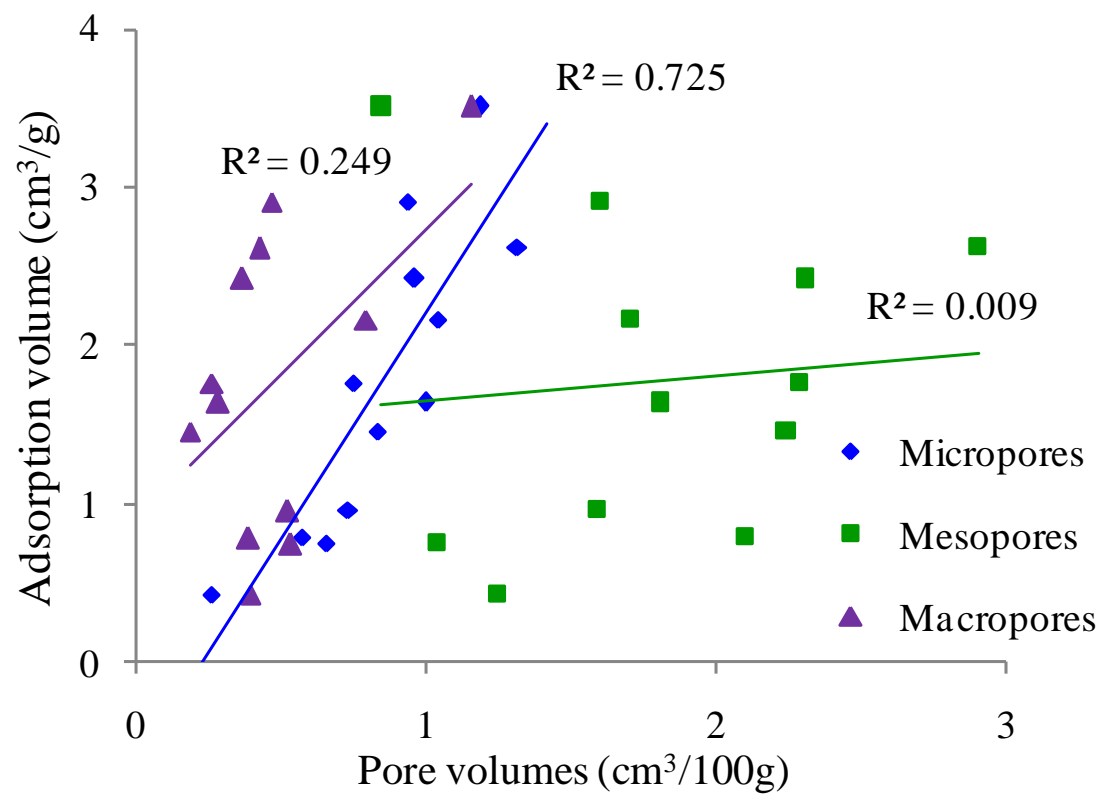

Fig. 13. Relationship between the methane sorption capacity and the pore volume of various pore scales. 


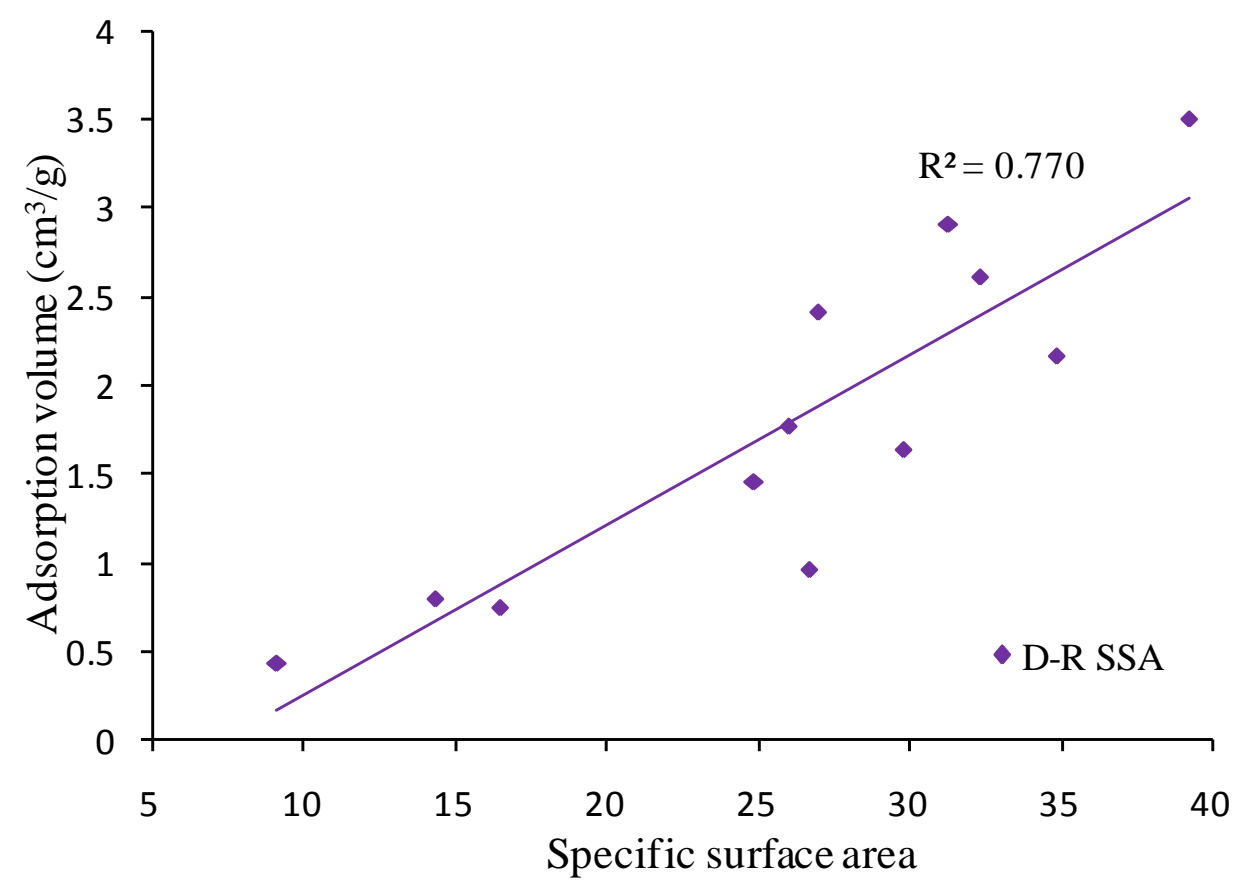

Fig. 14. Relationship between the methane sorption capacity and specific surface area (SSA). 